\title{
Biomass Partitioning and Accumulation in Tectona grandis (Teak) at Young Stage
}

\author{
S.M.C.U.P. Subasinghe ${ }^{1 *}$, K.A.J. Erandaka ${ }^{2}$ \\ ${ }^{I}$ Department of Forestry and Environmental Science, University of Sri Jayewardenepura, Sri Lanka \\ ${ }^{2}$ Sadaharitha Plantations Ltd, Sri Lanka \\ *upuls@sjp.ac.lk
}

\begin{abstract}
Forest biomass is considered to have a large potential for temporary and long-term carbon storage as biomass. Enhancement of biomass increase via forest plantation establishment can be considered as an effective method of mitigation of atmospheric carbon dioxide. However, due to the difficulty of measuring the below ground biomass accumulation, most of the tree and forest related biomass studies have been conducted on the above ground components of the trees. Therefore the present study was conducted to identify the biomass accumulation over the age and its partition in above and below ground segments of young teak trees by destructive sampling.
\end{abstract}

Teak trees of 55, 67, 79, 91 and 103 months growing in a single plantation in Puttlam was selected for this reason. Three trees of each age were randomly selected and carefully uprooted with the minimum damage to the roots. Then each tree was separated into main stem, primary, secondary and tertiary branches and roots and the weights were measured. Representative samples of each segment of the tree were oven dried at $72^{\circ} \mathrm{C}$ for three days. Then the biomass of each segment was calculated.

The average total tree biomass increased from 28.430 to $79.760 \mathrm{~kg}$ from 55 to 103 months. Comparatively, the highest biomass was recorded in the main stem $(63.5 \%)$ followed by primary branches $(15.7 \%)$. The third highest biomass was recorded from the roots $(11.7 \%)$ and the lowest biomass was recorded in tertiary branches (3.6\%). A strong exponential relationship was observed between the tree age and whole tree biomass increase with the $\mathrm{R}^{2}$ of $97.7 \%$. It further revealed that the biomass increase of teak is rising with a rapid rate even at the age of 10 years.

Keywords: Tree biomass, Biomass partition, Teak 